NASA/TM-2012-217273

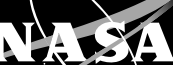

Nonlinear Dynamic Modeling and Controls

Development for Supersonic Propulsion System Research

Joseph W. Connolly, George Kopasakis, and Daniel E. Paxson

Glenn Research Center, Cleveland, Ohio

Eric Stuber

Georgia Institute of Technology, Atlanta, Georgia

Kyle Woolwine

The University of Colorado, Boulder, Colorado 


\section{NASA STI Program . . . in Profile}

Since its founding, NASA has been dedicated to the advancement of aeronautics and space science. The NASA Scientific and Technical Information (STI) program plays a key part in helping NASA maintain this important role.

The NASA STI Program operates under the auspices of the Agency Chief Information Officer. It collects, organizes, provides for archiving, and disseminates NASA's STI. The NASA STI program provides access to the NASA Aeronautics and Space Database and its public interface, the NASA Technical Reports Server, thus providing one of the largest collections of aeronautical and space science STI in the world. Results are published in both non-NASA channels and by NASA in the NASA STI Report Series, which includes the following report types:

- TECHNICAL PUBLICATION. Reports of completed research or a major significant phase of research that present the results of NASA programs and include extensive data or theoretical analysis. Includes compilations of significant scientific and technical data and information deemed to be of continuing reference value. NASA counterpart of peer-reviewed formal professional papers but has less stringent limitations on manuscript length and extent of graphic presentations.

- TECHNICAL MEMORANDUM. Scientific and technical findings that are preliminary or of specialized interest, e.g., quick release reports, working papers, and bibliographies that contain minimal annotation. Does not contain extensive analysis.

- CONTRACTOR REPORT. Scientific and technical findings by NASA-sponsored contractors and grantees.
- CONFERENCE PUBLICATION. Collected papers from scientific and technical conferences, symposia, seminars, or other meetings sponsored or cosponsored by NASA.

- SPECIAL PUBLICATION. Scientific, technical, or historical information from NASA programs, projects, and missions, often concerned with subjects having substantial public interest.

- TECHNICAL TRANSLATION. Englishlanguage translations of foreign scientific and technical material pertinent to NASA's mission.

Specialized services also include creating custom thesauri, building customized databases, organizing and publishing research results.

For more information about the NASA STI program, see the following:

- Access the NASA STI program home page at http://www.sti.nasa.gov

- E-mail your question via the Internet to help@ sti.nasa.gov

- Fax your question to the NASA STI Help Desk at $443-757-5803$

- Telephone the NASA STI Help Desk at 443-757-5802

- Write to: NASA Center for AeroSpace Information (CASI) 7115 Standard Drive Hanover, MD 21076-1320 
NASA/TM-2012-217273

,

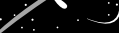

Nonlinear Dynamic Modeling and Controls

Development for Supersonic Propulsion System Research

Joseph W. Connolly, George Kopasakis, and Daniel E. Paxson

Glenn Research Center, Cleveland, Ohio

Eric Stuber

Georgia Institute of Technology, Atlanta, Georgia

Kyle Woolwine

The University of Colorado, Boulder, Colorado

Prepared for the

47th Joint Propulsion Conference and Exhibit

cosponsored by AIAA, ASME, SAE, and ASEE

San Diego, California, July 31-August 3, 2011

National Aeronautics and

Space Administration

Glenn Research Center

Cleveland, Ohio 44135 


\section{Acknowledgments}

The authors would like to express their gratitude to the Supersonics Project of the NASA Fundamental Aeronautics Program for supporting this research effort.

Trade names and trademarks are used in this report for identification only. Their usage does not constitute an official endorsement, either expressed or implied, by the National Aeronautics and Space Administration.

Level of Review: This material has been technically reviewed by technical management.

Available from

NASA Center for Aerospace Information 7115 Standard Drive

Hanover, MD 21076-1320
National Technical Information Service 5301 Shawnee Road Alexandria, VA 22312

Available electronically at http://www.sti.nasa.gov 


\title{
Nonlinear Dynamic Modeling and Controls Development for Supersonic Propulsion System Research
}

\author{
Joseph W. Connolly, George Kopasakis, and Daniel E. Paxson \\ National Aeronautics and Space Administration \\ Glenn Research Center \\ Cleveland, Ohio 44135 \\ Eric Stuber \\ Georgia Institute of Technology \\ Atlanta, Georgia 30332 \\ Kyle Woolwine \\ The University of Colorado \\ Boulder, Colorado 80301
}

\begin{abstract}
This paper covers the propulsion system component modeling and controls development of an integrated nonlinear dynamic simulation for an inlet and engine that can be used for an overall vehicle Aero-Propulso-Servo-Elastic (APSE) model. The focus here is on developing a methodology for the propulsion model integration, which allows for controls design that prevents inlet instabilities and minimizes the thrust oscillation experienced by the vehicle. Limiting thrust oscillations will be critical to avoid exciting vehicle aeroelastic modes. Model development includes both inlet normal shock position control and engine rotor speed control for a potential supersonic commercial transport. A loop shaping control design process is used that has previously been developed for the engine and verified on linear models, while a simpler approach is used for the inlet control design. Verification of the modeling approach is conducted by simulating a two-dimensional bifurcated inlet and a representative $\mathrm{J}-85$ jet engine previously used in a NASA supersonics project. Preliminary results are presented for the current supersonics project concept variable cycle turbofan engine design.
\end{abstract}

\section{Nomenclature}

$\begin{array}{llll}\text { 2DB } & \text { Two-Dimensional Bifurcated inlet } & \text { HSR } & \text { High Speed Research program } \\ A & \text { Cross-sectional area } & K & \text { Experimentally obtained bleed flow constant } \\ \text { AIP } & \text { Aerodynamic interface plane } & L & \text { Atmospheric disturbance wave length } \\ \text { APSE } & \text { Aero-propulso-servo-elasticity } & \text { LAPIN } & \text { Large Perturbation Inlet simulation } \\ \text { ASE } & \text { Aero-servo-elasticity } & M & \text { Mach number } \\ C_{\text {inlet }} & \text { Inlet controller transfer function } & \text { N+3 } & \text { Three generations forward from current state of the art } \\ \text { CFD } & \text { Computational fluid dynamics } & \text { NPSS } & \text { Numerical propulsion system simulation } \\ F & \text { Computational fluid dynamics flux vector } & P & \text { Pressure } \\ & & Q_{\text {source }} & \text { Heat addition }\end{array}$




$\begin{array}{ll}\text { Q1D } & \text { Quasi-one-dimensional } \\ \text { QFT } & \text { Quantitative feedback theory } \\ R & \text { Gas constant } \\ S & \text { Inlet source vector } \\ S^{\prime} & \text { Inlet bleed source vector } \\ T & \text { Temperature } \\ V & \text { Volume } \\ \text { VCE } & \text { Variable cycle engine } \\ W & \text { Inlet state vector } \\ e & \text { CFD internal energy term } \\ \dot{m} & \text { Mass flow rate } \\ s & \text { Laplace operator } \\ t & \text { Time } \\ u & \text { Velocity } \\ x & \text { Length } \\ \Delta & \text { Change in variable } \\ \alpha & \text { Artificial viscosity term }\end{array}$

$\begin{array}{ll}\gamma & \text { Ratio of specific heat } \\ \rho & \text { Density }\end{array}$

Subscript

$1 \quad$ Inlet plenum station 1

2 Inlet plenum station 2

c Corrected flow parameter

$n \quad$ Station location

$s \quad$ Static flow condition

$t \quad$ Total flow condition

$v \quad$ Engine volume gas parameter

P Plenum

Superscripts

engine Location of the first engine volume

inlet $_{\text {exit }}$ Location of the aerodynamic interface plane

\section{Introduction}

$\mathrm{U}^{\mathrm{N}}$ NDER the NASA Fundamental Aeronautics Program, the Supersonics Project aims to overcome the obstacles associated with supersonic commercial flight. Current work on this project is to develop the technologies to allow for practical supersonic commercial flight at approximately Mach 2. The proposed vehicles are long, slim body aircraft with the potential for pronounced structural vibrations known as aeroservo-elastic modes (ASE). ${ }^{1,2}$ When coupled with propulsion system dynamics, the modes are known as aero-propulso-servo-elasticity (APSE). The APSE considerations can lead to design challenges pertaining to aircraft performance such as aircraft ride quality and stability. Furthermore, other disturbances upstream of the inlet generated by atmospheric wind gusts may also affect ride quality and stability. To study the propulsion component of APSE, an integrated nonlinear model was developed that includes both the inlet and engine propulsion system dynamics.

The modeling approach used for the component dynamic models has previously been developed ${ }^{3,4}$ and verification of inlet and engine integration modeling approach leverages work conducted under the NASA High Speed Research (HSR) project for an integrated mixed compression inlet and J-85 turbojet engine. ${ }^{5}$ The previous integrated inlet and engine was developed under HSR in the FORTRAN computer language. A legacy inlet code, LArge Perturbation INlet (LAPIN), and engine code the Aerodynamic Turbine Engine Code (ATEC) ${ }^{6,}{ }^{7}$ were used for the model integration. LAPIN is used as a key verification tool in the current development of the inlet model. Other integrated propulsion system simulations have been created by Gamble, Numbers, and Giannola ${ }^{8,9,10}$. The distinction in the work presented here is that the main goal is to provide a platform for control algorithm testing, in the context of changing design concepts for the supersonic propulsion system and integration into an ASE vehicle model. Under this goal the objective was to have a highly modular code built on a platform that is familiar to controls engineers. To this end the MATLABß Simulink $®$ software was chosen.

The purpose of the supersonic inlet is to supply the engine with the required mass flow at a subsonic speed with high total pressure and minimum distortion. The inlet is modeled using a quasi-one dimensional (Q1D) implementation of the Euler equations. The engine comprises another major component of the overall propulsion system and is connected just downstream of the inlet flow path. Currently, the engine model uses a single lumped volume for each of the major components, such as the compressor, combustor, turbine, and afterburner-nozzle. The propulsion system controller is a third major component to the simulation. To study propulsion system controller effectiveness in maintaining the desired ride quality and stability, atmospheric turbulence models ${ }^{11,12}$ are used to investigate the impact of free stream flow disturbances on the propulsion system.

The engine control design approach is based on classical loop shaping, ${ }^{13}$ and quantitative feedback theory (QFT) methodologies laid out by Houpis. ${ }^{14}$ The latter accounts for design specifications in terms of bounds in a loop shaping development approach. ${ }^{15}$ The loop shaping approach used here is a linear controls design methodology that requires the nonlinear propulsion models to be linearized prior to the development of 
control algorithms. The inlet control algorithm development used a Proportional Integral Derivative (PID) design that will be discussed in more detail subsequently. The developed algorithms are later tuned for implementation in the nonlinear model.

The overall paper objectives are as follows:

- Provide an overview of a propulsion system model for a supersonic vehicle, with the focus on integration of the inlet and engine.

- Illustrate the key features of the propulsion system model to support developing and designing control algorithms.

- Provide an example control case of using an inlet bypass door and an engine fuel injector to dampen out atmospheric disturbances, thus limiting thrust oscillations and allowing for stable operation.

\section{Model Overview}

The overall APSE simulation block diagram can be seen in Fig. 1. The propulsion system of the overall model, highlighted in Fig. 1, is comprised of the nonlinear inlet, engine, and propulsion controllers. ASE vehicle impacts are neglected in this study, but are illustrated by dashed lines in Fig. 1 to provide an overview of how the propulsion system fits into the larger APSE simulation architecture. All of the propulsion elements are modeled using unsteady conservation equations, described in the following sections. This allows for the investigation of inlet stability and thrust oscillations. To run the simulation, free stream static conditions of pressure, temperature, and Mach number are applied to the inlet model. The inlet model then calculates an exit total pressure and temperature, while controlling the terminal shock to maintain stability. Airflow properties at the inlet exit or aerodynamic interface plane (AIP) are used as the engine face input conditions, which establishes the key propulsion system's integration point that is required for the two models. The engine then uses the input conditions, its performance maps, and a modified version of the Euler conservation equations to calculate the engine output thrust. The integrated model allows the engine simulation to initiate an AIP disturbance that impacts inlet shock stability.

The overall goal of the ASE project is to integrate a high fidelity vehicle and propulsion system model to investigate aero-elastic effects. The work presented here is a step along that path, providing a dynamic propulsion system simulation that is suitable for controls development and testing. Previous work in the area of APSE has focused on either the vehicle or the propulsion system, but rarely both, unless considering a hypersonic vehicle where the vehicle itself provides compression of the flow feeding into

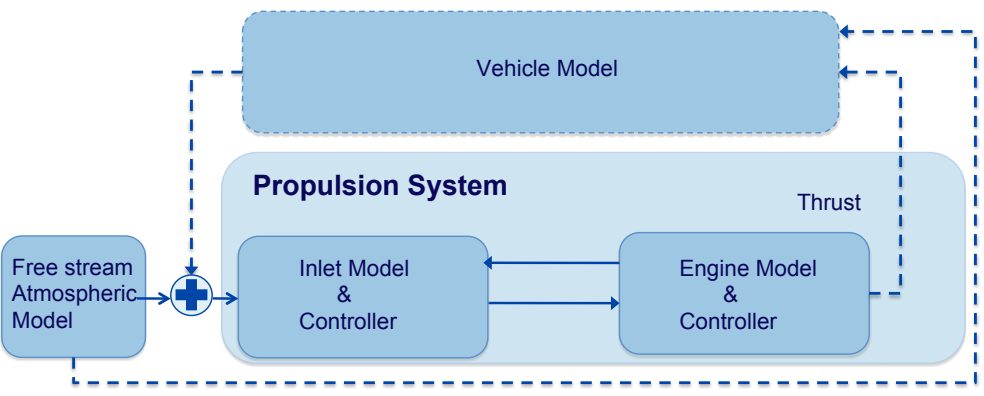

Figure 1. Block diagram of overall APSE system model with propulsion system highlighted.

the propulsion system. ${ }^{16-18}$

\section{A. Inlet Model}

\section{Analysis}

The inlet modeling methodology verification in this study was done using a simulation of the HSR project's two-dimensional bifurcated (2DB) mixed compression inlet. ${ }^{19}$ Work is currently ongoing to transition the current design to an external compression inlet. However, the mixed compression design will be used for the remainder of this study to illustrate the modeling approach. ${ }^{20} \mathrm{~A}$ mixed compression inlet is more complex due to the need to control the normal shock downstream of the inlet throat. If the normal shock moves upstream of the throat, it will be ejected from the inlet. This is known as an inlet unstart and results in a sudden loss of thrust. A schematic of the 2DB inlet can be seen in Fig. 2, which illustrates the desired region to control the normal shock and the bypass door actuator that controls the normal shock position by altering the mass flow.

The inlet model developed using MATLAB Simulink software uses computational fluid dynamics (CFD) based numerical techniques to integrate the Q1D form of the Euler equations to model the dynamic flow 
properties of the inlet. A schematic of the modeling approach can be seen in Fig. 3, where over a small distance, $d x$, the fluid properties change by a differential amount. The model assumes a calorically perfect gas. In addition, the code includes simple models of mass flow bleed and bypass. The bypass door is modeled as a choked bleed, since the main purpose of the bypass door is to release mass from the inlet. The bypass and bleed models will remove mass from the inlet core flow as illustrated in Fig. 3.

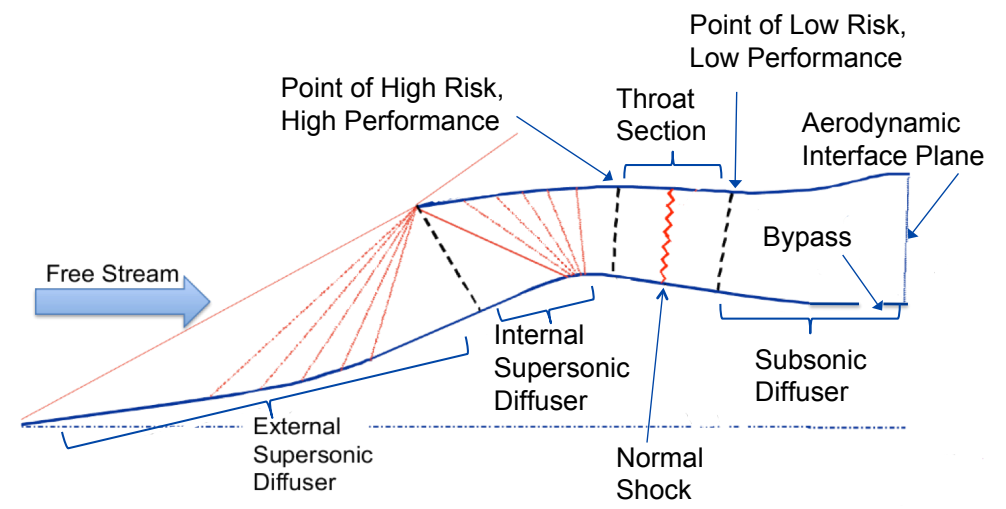

Figure 2. 2DB inlet schematic illustrating shock patterns and the location of the bypass door near the AIP.

A brief synopsis of the modeling approach is provided here, without consideration for bleed or bypass as these will be discussed in the following section. The approach uses the conservation equations of continuity, momentum, and energy, Eqs. (1) to (3), respectively: ${ }^{21}$

$$
\begin{array}{r}
\frac{\partial(\rho A)}{\partial t}+\frac{\partial(\rho u A)}{\partial x}=0 \\
\frac{\partial(\rho u A)}{\partial t}+\frac{\partial\left[A\left(\rho u^{2}+P\right)\right]}{\partial x}=P \frac{\partial A}{\partial x} \\
\frac{\partial\left[\frac{P A}{\gamma-1}+\frac{\rho u^{2} A}{2}\right]}{\partial t}+\frac{\partial\left[A\left(\frac{P u \gamma}{\gamma-1}+\frac{\rho u^{3}}{2}\right)\right]}{\partial x}=0
\end{array}
$$

Figure 3. Q1D flow representation of differential volume.

The above governing equations are implemented in the simulation assuming that $\frac{\partial A}{\partial t}=0$. This requires the inlet geometry to be fixed during the simulation. This is acceptable because geometry conditions change very slowly when compared to supersonic flow. The resulting state, flux, and source vectors are provided below, Eqs. (4) to (6):

$$
\begin{gathered}
\boldsymbol{W}=\left[\begin{array}{c}
\rho \\
\rho u \\
\frac{P}{\gamma-1}+\frac{\rho u^{2}}{2}
\end{array}\right] \\
\boldsymbol{F}=\left[\begin{array}{c}
\rho u \\
P+\rho u^{2} \\
\frac{P u \gamma}{\gamma-1}+\frac{\rho u^{3}}{2}
\end{array}\right] \\
\boldsymbol{S}=\left[\begin{array}{c}
0 \\
P \frac{d A}{d x} \\
0
\end{array}\right]
\end{gathered}
$$

The overall governing equation is expressed in vector form in Eq. (7): 


$$
\frac{\partial \boldsymbol{W}}{\partial t}=-\frac{1}{A} \frac{\partial A \boldsymbol{F}}{\partial x}+\frac{\boldsymbol{S}}{A}
$$

In the model, Eq. (7) is integrated numerically using a Runge-Kutta time marching scheme with central differences of the spatial terms. To increase stability in the vicinity of shocks, an artificial viscosity term is included to dampen out non-physical oscillations. This is used to smooth out numerical oscillations about the discontinuity of the normal shock. ${ }^{21}$ The coefficient, $\alpha$, is carefully chosen such that dampening occurs but the associated diffusion does not degrade the formal accuracy of the numerical scheme. The numerical viscosity term is essentially the equivalent of adding diffusion to the governing equations as shown in Eq. (8)

$$
\alpha \frac{\partial^{2} A W}{\partial x^{2}}
$$

The governing equation is then updated to become Eq. (9):

$$
\frac{\partial \boldsymbol{W}}{\partial t}=-\frac{1}{A} \frac{\partial A \boldsymbol{F}-\alpha \frac{\partial A \boldsymbol{W}}{\partial x}}{\partial x}+\frac{\boldsymbol{S}}{A}
$$

\section{Bleed and Bypass Model}

Bleed zones and bypass gates are implemented throughout the inlet to control and maintain the position of the normal shock. The bleed sections are passive and add stability for the normal shock, while the bypass door is placed near the AIP for closed loop control of the normal shock position. Bleed zone gas states are calculated using the total pressure and total temperature of the grid point with an associated plenum that can fill to reduce the mass flowing in the main inlet duct section as illustrated in Fig. 4. The bleed zone plenums are required since the bleed flow from the main duct is not choked (Station 1). This allows flow to move in and out of the main duct from the plenum. The exit of the plenum into the free stream is assumed to be choked (Station 2). Each bleed section has its own plenum. The mass accumulates in the plenum, where the flow velocity is assumed to be zero. ${ }^{22}$

The governing equations used for the bleed plenum models are continuity Eq. (10) and energy Eq. (11), which are tied together by the state equation, Eq. (12). These equations are used to solve the gas properties at the stations referred to in Fig. $4 .^{22}$

$$
\begin{array}{r}
\frac{d \rho_{P}}{d t}=\frac{1}{V_{P}}\left(\dot{m}_{1}-\dot{m}_{2}\right) \\
\frac{d T_{P}}{d t}=\frac{1}{V_{P} \rho_{P}}\left[\left(\gamma T_{t 1}-T_{P}\right) \dot{m}_{1}-(\gamma-1) T_{P} \dot{m}_{2}\right] \\
P_{P}=\rho_{P} R T_{P}
\end{array}
$$

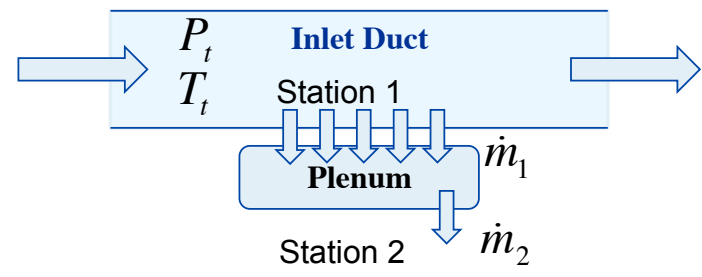

Figure 4. Bleed model schematic with associated plenum volume, where the flow is unchoked at station one and choked at station two.

Bleed flow rates are determined using an experimentally found variable discharge coefficient $K$. Equation (13) is used to determine the flow rates at station 1 and station 2, along with the gas parameters at the given station. ${ }^{22}$

$$
\dot{m}=K \frac{P_{t} A}{\sqrt{\gamma R T_{t}}} \frac{\sqrt{\gamma}}{\left[1+\frac{\gamma+1}{2}\right]^{\frac{\gamma+1}{2(\gamma-1)}}}
$$

The variable $K$ is a function of bleed hole area, boundary layer, and Mach number. At station 1 the discharge coefficient is also a function of the pressure ratio across the bleed hole to account for the unchoked mass flow. Alternatively, an unchoked mass flow equation could be used at station 1, such as that found in Hill. ${ }^{23}$

The bypass door is modeled such that the flow out of the bypass door from station 1 is assumed to be choked. This eliminates the need for a bypass door plenum model. Additional source terms due to the bleed 
and bypass are illustrated in Eq. (14). The new source is applied to the overall inlet governing equations by adding to the previous source vector Eq. $(6) .{ }^{22}$

$$
\boldsymbol{S}^{\prime}=-\left[\begin{array}{c}
\frac{\dot{m}_{1}}{A_{n} \Delta x_{n}} \\
\frac{\dot{m}_{1} u_{n}}{A_{n} \Delta x_{n}} \\
\frac{\dot{m}_{1}\left[\frac{\gamma P_{n}}{(\gamma-1) \rho_{n}}+\frac{u_{n}^{2}}{2}\right]}{A_{n} \Delta x_{n}}
\end{array}\right]
$$

\section{Inlet Model Verification}

To verify the dynamic behavior associated with the present Simulink inlet simulation, the LAPIN flow code is used to represent the "true" solution. ${ }^{22}$ LAPIN is a sophisticated high-resolution, Q1D code capable of modeling core flow instabilities, inlet control actuators, and geometric variations. However, it does not readily lend itself to test closed loop control algorithms. Requirements for inlet integration with other models and control algorithm verification prompted development of a nonlinear inlet model using Simulink software to focus on control algorithm verification and integration with other models. A more detailed description and validation of the Simulink inlet model is forthcoming in Kopasakis. ${ }^{20}$

The inlet Simulink simulation was first setup to model the same 134 grid points used in LAPIN. However, long simulation times motivated the need for a reduction in the grid points to reduce simulation time, while maintaining a normal shock position to agree with LAPIN calculations within 1.5\%. This resulted in a model with 87 grid points, the majority of which are in the supersonic portion of the inlet. The upstream flow properties are static pressure, static temperature, and Mach number. An exit Mach number is used for the downstream boundary condition. To demonstrate the Simulink model's ability to match LAPIN results, the two models were simulated at a cruise operating point. A free stream operating condition was chosen representing 18,288 $\mathrm{m}$ (60,000 ft) cruise altitude at a flight speed of Mach 2.35 and an exit Mach of 0.45 .

The average percent difference between the steady state LAPIN results and the Simulink simulation across all grid points are provided in Table 1 for both the 134 and 87 grid point models. It can be seen that the Simulink simulation is comparable to LAPIN when using the same grid points and only introduces a worst-case average for the static pressure calculation of a $3 \%$ difference with reduced grid points. Steady state plots of the static pressure, static temperature, density, and Mach number can be seen in Fig. 5. The axial location of the inlet starts at the "0 m" location representing the start of the external compression. The external compression is assumed to oc-
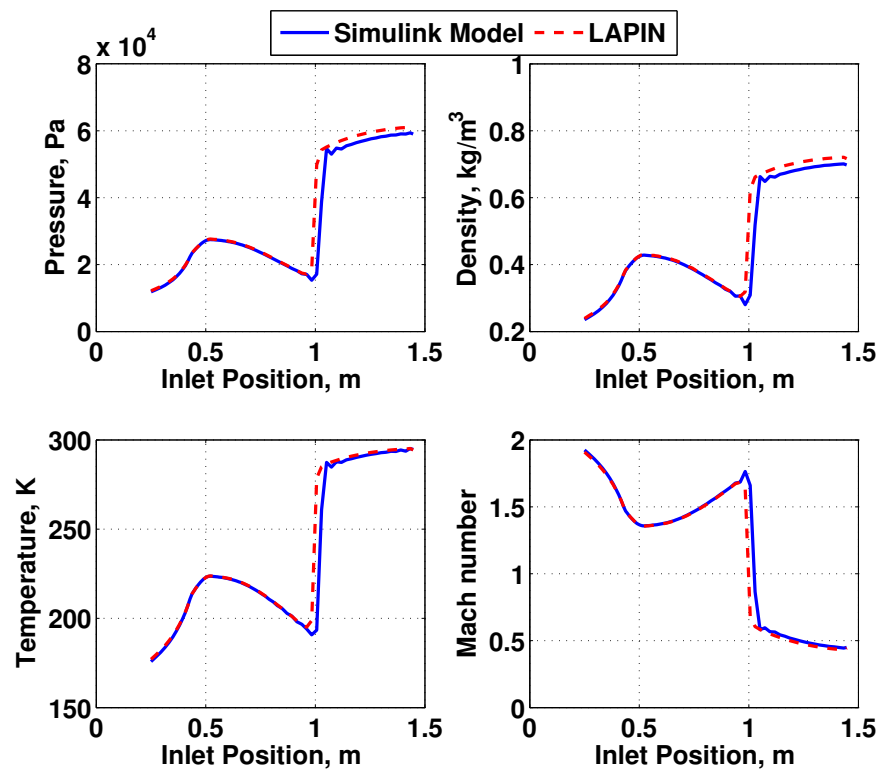

Figure 5. Inlet steady state plots of static pressure, static temperature, static density, and mach number for the Simulink software model compared to LAPIN simulation results across inlet axial stations. cur much faster than actuator movement, and thus will not be considered to impact the simulation dynamics. This allows only oblique shock relations to be used in the region upstream of the cowl lip. The CFD is used for the internal portion of the inlet starting downstream of the cowl lip located at " $0.25 \mathrm{~m}$ ". The AIP is located at " $1.45 \mathrm{~m}$ " where 
the engine face would be located. The plots in Fig. 5 show a high level of agreement between the Simulink model and LAPIN across all axial locations of the inlet, with the data traces lying nearly on top of each other.

Table 1. Average percent difference between LAPIN simulation results and Simulink inlet simulation results using 87 and 134 inlet grid points.

\begin{tabular}{|c|c|c|c|c|}
\hline $\begin{array}{c}\text { Simulink } \\
\text { Inlet Grid }\end{array}$ & $\begin{array}{c}\text { Static } \\
\text { Pressure }\end{array}$ & $\begin{array}{c}\text { Static } \\
\text { Temperature }\end{array}$ & $\begin{array}{c}\text { Static } \\
\text { Density }\end{array}$ & $\begin{array}{c}\text { Shock } \\
\text { Position }\end{array}$ \\
\hline 87 points & $3.07 \%$ & $0.94 \%$ & $2.15 \%$ & $1.38 \%$ \\
\hline 134 points & $0.80 \%$ & $0.51 \%$ & $0.58 \%$ & $0.63 \%$ \\
\hline
\end{tabular}

A Bode plot is used to illustrate the dynamic simulation results of the LAPIN and Simulink simulations in Fig. 6 . These plots show a high level of agreement between the two models. The Bode plot is for an exit static pressure response resulting from a $3 \%$ amplitude sinusoidal logarithmic free stream pressure disturbance, chosen for illustrative purposes. The sinusoid starts at $20 \mathrm{~Hz}$ and ends at $200 \mathrm{~Hz}$ after ten seconds of simulation time. The phase and coherence of the two models are almost identical, while the magnitudes of the Bode plots starts to show a small deviation at frequencies greater than $100 \mathrm{~Hz}$.
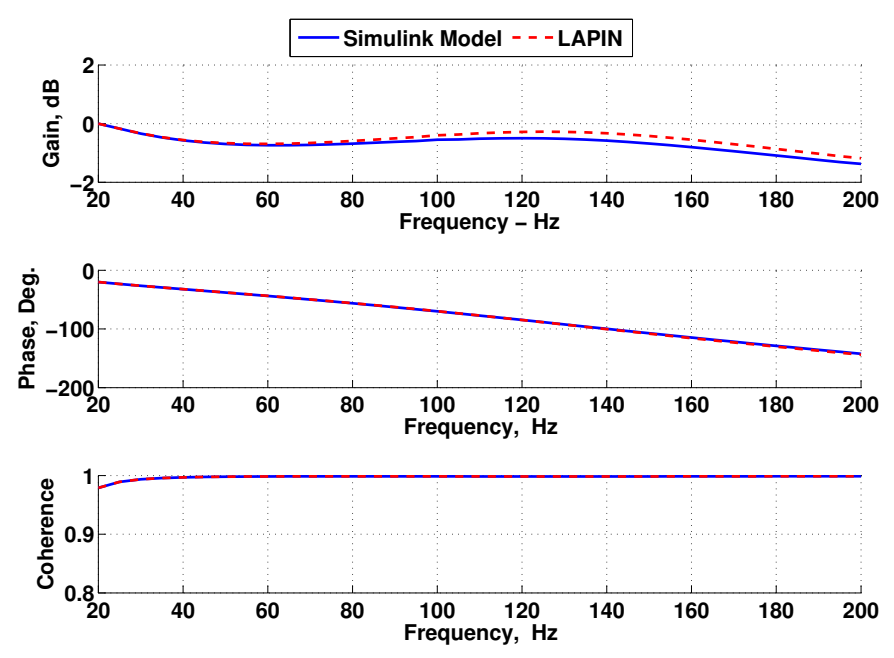

Figure 6. Inlet model using Simulink software exit pressure bode plot for a logarithmic free stream pressure disturbance of $20 \mathrm{~Hz}$ to $200 \mathrm{~Hz}$ and the resulting coherence versus a LAPIN simulation bode plot.

\section{B. Engine Model}

The engine comprises the other major component of the overall propulsion system, and is connected just downstream from the inlet. Initially, the modeling effort in this paper will use a turbojet engine similar to the General Electric J-85 for verification. More relevant supersonic engine concepts will be considered in the following section. The J-85 lends itself to a straightforward model development and verification because it has not only undergone extensive testing at NASA Glenn Research Center ${ }^{24}$, but many of the required performance parameters are accessible as well.

The turbojet model uses a single lumped volume for each of the major components such as compressor, combustor, turbine, afterburner, and nozzle. The modeling approach is outlined in Seldner ${ }^{25}$ and refined in Kopasakis. ${ }^{3}$ The high level equations are defined here for completeness and understanding the level of fidelity of the nonlinear simulation, which is integrated into the overall propulsion model. Most of the geometric information for the engine is obtained from previous work done by Tesch. ${ }^{26}$ Each of the fluid flow components is modeled using a set of derived conservation equations modified from the standard Euler form and written as continuity, momentum, and energy, Eqs. (15) to (17), respectively. These equations are integrated numerically using a time marching scheme and the Seldner differencing technique of the spacial terms. ${ }^{3}$ 


$$
\begin{array}{r}
\frac{d}{d t}\left(\rho_{s}\right)=-\frac{1}{V} \Delta \dot{m} \\
\frac{d}{d t}(\dot{m})=-\frac{A}{\Delta x} \Delta P_{s} \\
\frac{d}{d t}\left(\rho_{s} T_{t}\right)=-\frac{\gamma}{V} \Delta\left(T_{t} \dot{m}\right)
\end{array}
$$

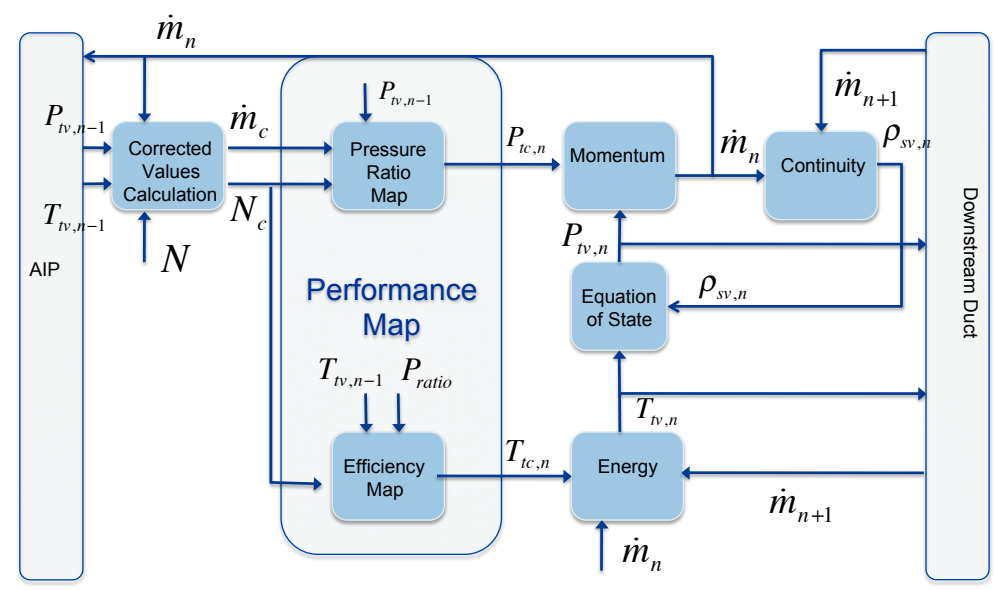

Figure 7. Turbine engine compressor component modeling schematic. sive component is shown in Fig. 7. This schematic is analogous to the other major components, with the exception of various performance maps, which may be required to meet characteristic flow parameters. The variables are left generic and the subscript "n" is associated with the current volume component. The conditions of the engine component upstream are used with performance maps to generate characteristic values for this particular engine design. The performance map is actually two table lookups in the model to obtain a given pressure ratio and efficiency, which are then used to get the characteristic pressure and temperature. The characteristic values are then used with the associated variation of the engine governing Eqs. (15) to (17) to obtain the state values that are passed to the subsequent engine component.

\section{Next Three Generations (N+3) Engine Design Concept}

The current engine design concept of the supersonic propulsion system is a Variable Cycle Turbofan Engine (VCE). The overall modeling approach is the exact same as the turbojet described above, with the exception that there is a more complicated flow path. The flow coming from the inlet goes through the fan component and is split into three gas paths as illustrated in Fig. 8. The primary gas path is nearly identical to the turbojet and goes through the core of the engine. The secondary gas path is similar to a typical turbofan engine in that a large amount of the flow is bypassed around the core of the engine. This secondary flow is mixed downstream of the turbine and exhausted out a common nozzle with the core flow. The more advance concept part of this engine is a third gas path that exhausts through a
A compressive component modeling approach is discussed in more detail in this section. This is done to provide context for the modifications of the boundary conditions required for inlet-engine model integration. Integration will be discussed subsequently. The three state variables chosen for the model of each component are the static density, static density times the total temperature, and mass flow rate. Since this is a subsonic system, information from two of the states must travel downstream, while the other travels upstream. Here the mass flow rate information travels upstream and the temperature and pressure travel downstream. A general schematic of the overall modeling approach for a compres-

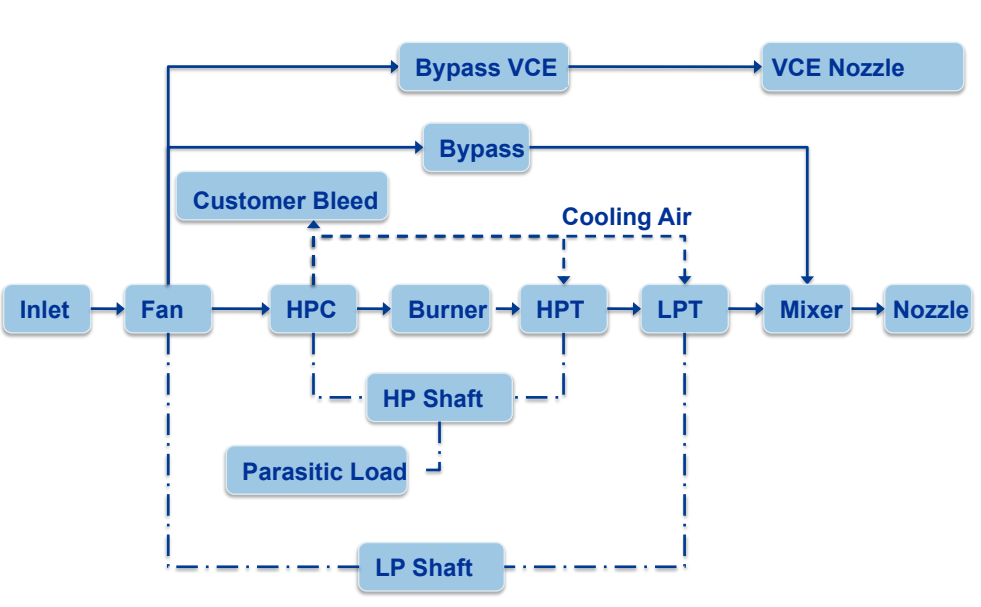

Figure 8. $\mathrm{N}+3$ engine design concept for a variable cycle engine. 
different nozzle. This path provides a lower exit velocity that could be used as a noise shield for the flow exiting the main nozzle. While Fig. 8 shows all of the major engine components that have their own conservation equations, in between each component is also an associated connecting duct that is not shown in the figure for simplicity. Each of these ducts are also modeled using the governing conservation equations.

The initial conditions and geometry information to initiate the N+3 VCE comes from a design concept implemented in the Numerical Propulsion System Simulation (NPSS). A cruise operating point was chosen at $15,240 \mathrm{~m}(50,000 \mathrm{ft})$ and a Mach number of 1.6. A choked nozzle flow equation is used for the exit boundary condition. The average steady state percent difference between the NPSS model and the Simulink model is illustrated in Table 2 for the state parameters across all of the engine components. The main parameter of interest for this study is the thrust, calculated here as the gross thrust, which deviates from NPSS calculations by only $1.04 \%$. Thrust is important because it will be the feedback parameter when the propulsion system is integrated with the vehicle model.

Table 2. Average percent difference between variable cycle turbofan engine Simulink simulaton results and NPSS model results across all components and ducts.

\begin{tabular}{|c|c|c|c|}
\hline $\begin{array}{c}\text { Total } \\
\text { Pressure }\end{array}$ & $\begin{array}{c}\text { Total } \\
\text { Temperature }\end{array}$ & $\begin{array}{c}\text { Mass } \\
\text { Flow }\end{array}$ & $\begin{array}{c}\text { Gross } \\
\text { Thrust }\end{array}$ \\
\hline $0.97 \%$ & $1.05 \%$ & $1.67 \%$ & $1.04 \%$ \\
\hline
\end{tabular}

\section{Inlet and Engine Integration}

A complete propulsion system simulation has the nonlinear inlet model coupled with the nonlinear dynamic engine model. The integrated nonlinear propulsion system used in this study includes the simulated 2DB inlet and a representative J-85 engine models. This allows for the development of the modeling approach, control concepts, and interfaces for the overall propulsion system integration. Ultimately an external compression inlet needs to be developed and integrated with the N+3 VCE to have a more accurate picture of how atmospheric disturbances will impact thrust for the current supersonics design concepts.

The integration approach is to keep the engine model input boundary condition the same, thus expecting a total pressure and total temperature. The AIP boundary condition of the inlet is removed and replaced with a very small duct volume that can be integrated into the engine simulation. The duct volume is modeled similarly to the ducts in the N+3 VCE engine, where the conservation equations become Eqs. (18) to (20).

$$
\begin{array}{r}
\frac{d}{d t}\left(\rho_{s}\right)=\frac{1}{V}\left(\dot{m}^{\text {inlet }_{\text {exit }}}-\dot{m}^{\text {engine }}\right) \\
\frac{d}{d t}(\dot{m})=\frac{A}{x}\left(P_{s}^{\text {inlet }_{\text {exit }-1}}-P_{s}^{\text {inlet }_{\text {exit }}}\right) \\
\frac{d}{d t}\left(\rho_{s} T_{t}\right)=\frac{\gamma}{V}\left(T_{t}^{\text {inlet }_{\text {exit }-1}} \dot{m}^{\text {inlet }_{\text {exit }}}-T_{t}^{\text {inlet }_{\text {exit }}} \dot{m}^{\text {engine }}\right)
\end{array}
$$

The volume that includes the AIP uses its calculated states to output the total pressure and total temperature required for the engine. In addition, the removal of the Mach number AIP boundary of the inlet requires information of the engine mass flow rate to be accepted as the engine feedback information using standard gas property relations.

The superscripts used in the above equations indicate the location of the variable relative to the AIP and engine face. These equations are then tied together using the state equation, Eq. (12), to obtain the inlet exit state variables for the downstream engine face and the upstream inlet grid points.

\section{Disturbance Models}

The primary source of disturbances investigated in this study are upstream flow perturbations due to atmospheric wind gusts, using the atmospheric model outlined in Kopasakis. ${ }^{11,12}$ An advantage of this atmospheric model is that it allows for time domain simulation of disturbances that are fractional order. These disturbances are used in determining the effectiveness of the control to limit thrust oscillations and, in the case of the mixed compression inlet, avoid an unstart condition. For this control design, an important goal is to assess the worst possible disturbance that the propulsion system is expected to encounter during 
operation. Due to the difficult nature of defining a worst-case for atmospheric disturbances, a representative severe-case scenario is obtained from an approach where several sinusoidal wind gust waves are summed to obtain a repeating pattern that can be used to test the control algorithm. The highest frequency wind gusts based on the vehicle speed and altitude are on the order of tens of hertz.

\section{E. Controller}

The engine control design used in this study has aspects of classical loop shaping ${ }^{13}$ design and Quantitative Feedback Theory. ${ }^{27}$ The engine controller for the shaft speed was first designed on linear models, ${ }^{15}$ and later implemented in the nonlinear model turbojet and the N+3 VCE model with a slight reduction in the gain to improve stability. The shaft speed is controlled using the engine fuel injector that has a bandwidth of $6 \mathrm{~Hz}$. In addition, the turbojet and VCE engine design both have variable nozzle and compressor guide vanes that are set on schedules and not actively controlled. The bandwidth of approximately $6 \mathrm{~Hz}$ for a fuel injector will not be able to attenuate disturbances in the tens of hertz. This results in the inlet bypass door being the primary means to attenuate the higher frequency disturbances and reduce thrust oscillations ${ }^{28,} .{ }^{29}$

A controller for the 2DB inlet normal shock position was developed using the same approach based on linear models obtained from LAPIN. ${ }^{28}$ The control design uses a bypass door actuator with a bandwidth of approximately $175 \mathrm{~Hz}$, which is modeled using a simple transfer function. ${ }^{15}$ However, the control design from the previous work encountered stability issues when implemented in the Simulink model. This could be a result from the change in the model's operating point combined with the change to control the normal shock closer to the throat and thus altered the linear operating point from which the controller was designed. Therefore an alternate PID controller with a low pass filter was designed, but with a lower bandwidth. The transfer function of the PID controller is listed in Eq. (21).

$$
C_{\text {inlet }}=0.0148+6.0482 \frac{1}{s}-\left(3.7 \times 10^{-5}\right) \frac{165.5}{1+165.5 \frac{1}{s}}
$$

The controller's lower bandwidth results in an inability to attenuate high frequency disturbances (on the order of tens of hertz) that could be encountered in either the atmospheric or ASE disturbances. While this is a concern, the emphasis here is propulsion system integration to provide a platform for control design, rather than a detailed control development. Also, current concepts for use of an external compression inlet will not have a bypass door due to the lack of a need to control the normal shock and thus will not be able to actively attenuate the high frequency disturbances as well.

\section{Results}

The purpose of these simulation results is to demonstrate the integrated propulsion system model with an included controller. The example simulation results investigate the impact of atmospheric disturbances on the normal shock position and thrust oscillations from the propulsion models about a cruise operating point. Presentation of the results is divided into three sections that represent the main propulsion system platforms. The first section will investigate the 2DB inlet model alone for its ability to use the bypass door to control the normal shock position in the inlet, second the integrated 2DB inlet and representative J-85 engine model will be used to investigate a fully integrated supersonic propulsion system's thrust oscillations, and finally a preliminary look at a current concept VCE engine model will be used to investigate thrust oscillations.

\section{A. Inlet Results}

The Simulink based 2DB inlet model is simulated at a cruise condition at 18,288 $\mathrm{m}(60,000 \mathrm{ft})$ and a flight Mach number of 2.35. The AIP boundary condition is set to a Mach number of 0.45 . The normal shock is commanded at the $1 \mathrm{~m}$ location of the inlet for illustrative purposes. To provide a visual reference Fig. 2 can be used where $0 \mathrm{~m}$ would refer to the start of the inlet, $0.25 \mathrm{~m}$ would refer to the start of the internal section of the inlet, $0.66 \mathrm{~m}$ refers to the minimum area or throat of the inlet, and the AIP would be at 1.45 $\mathrm{m}$. The closed loop controller moved the normal shock position upstream and downstream from its nominal $1 \mathrm{~m}$ location due to a commanded position change of $\pm 3 \%$ from nominal, illustrated in Fig. 9. The normal shock position is shown to have a very good response with no overshoot. While the ability to command the shock to the desired location provides some confidence in the PID controller, the goal is to attenuate atmospheric disturbances. 
The atmospheric turbulence model is used at the cruise condition to provide disturbances to the input boundary conditions of temperature, Mach number, and pressure. The boundary condition disturbances are illustrated in Fig. 10. A sum of sinusoids creates repeating disturbances that are representative of the one-second time slice shown in Fig. 10. The main thing to take away from this plot is the large drop in boundary condition values at the six second mark. This atmospheric disturbance was used for both the inlet simulation results and the integrated inlet-engine simulation results.

The atmospheric disturbance results in a large normal shock movement for the open loop inlet as seen in Fig. 11. The open loop normal shock response oscillates about the $1 \mathrm{~m}$ location; however, the large drop in free stream conditions at the six second mark causes the normal shock to move to the throat location of $0.66 \mathrm{~m}$. This is a marginally stable location for the normal shock, meaning that even slightly larger perturbations could cause the normal shock to be ejected from the inlet, causing an unstart condition. This is a dramatic event that results in sudden loss of thrust, and could create large ASE modes.
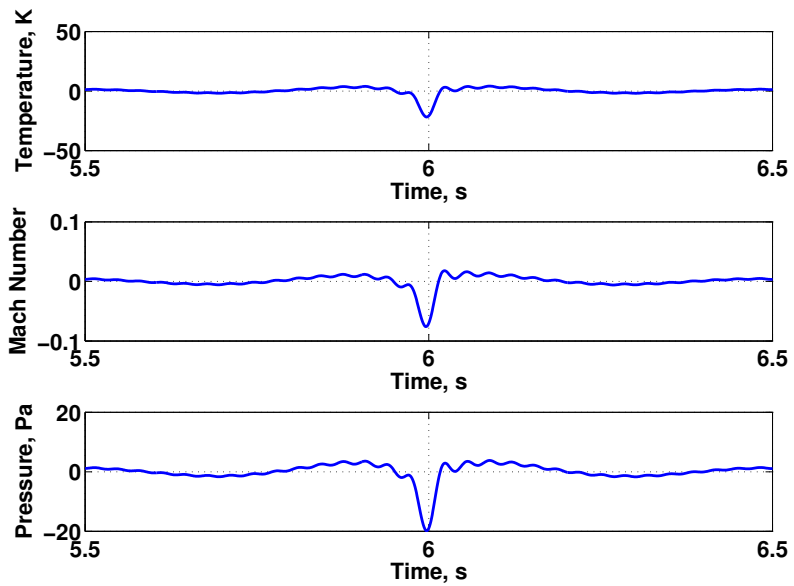

Figure 10. Simulated free stream perturbations based on atmospheric disturbance model wind gusts .

The introduction of the closed loop normal shock control greatly attenuates the affects of the atmospheric disturbance as shown in Fig. 11. The controlled bypass door attenuates the normal shock movement throughout the one-second repeating period of the atmospheric disturbances. The large transient that nearly caused the open loop response to unstart only causes the controlled normal shock response to move $0.08 \mathrm{~m}$ upstream from the commanded position and $0.1 \mathrm{~m}$ in the relatively benign downstream direction. This control design for the bypass door, provided a very desirable response to the disturbance. Further development of the controller could allow for the normal shock to be commanded closer to the throat instead of the chosen $1 \mathrm{~m}$ illustrative location. Also, given that these are atmospheric disturbances, it is difficult to determine

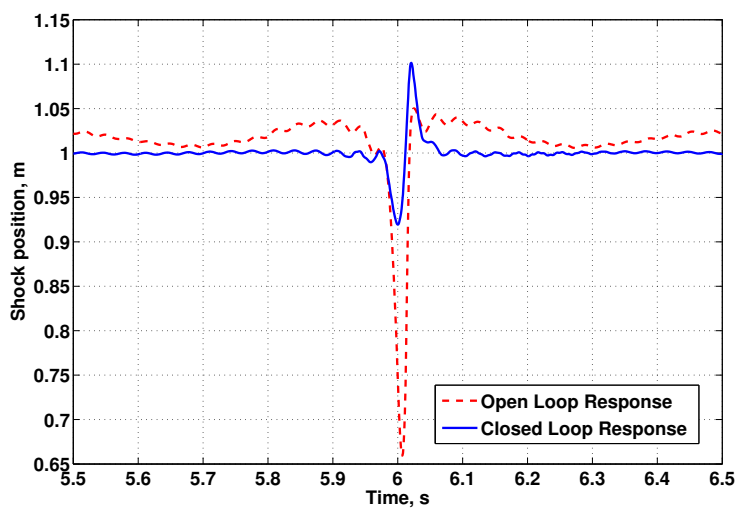

Figure 11. Simulated inlet open-loop and closed-loop normal shock position response to an atmospheric disturbance. exactly the worst-case disturbance, thus the disturbances here are best classified as severe. 


\section{B. Integrated Inlet and Turbojet Engine Results}

The integrated model investigates the closed loop response of the 2DB inlet simulation and representative J-85 engine model to the atmospheric disturbance described in the inlet section. The operating condition is representative of a cruise condition at 19,812 $\mathrm{m}(65,000 \mathrm{ft})$. This condition was chosen for the operating point as it represents a wind tunnel test condition in which the specified components were tested in the NASA Glenn Research Center 10x10 supersonic wind tunnel. The integrated model only focuses on the closed loop response, because the open loop response that caused the inlet to nearly unstart introduced oscillations that can cause the integrated model to have instabilities. The inlet normal shock position is still commanded to the $1 \mathrm{~m}$ location as can be seen in Fig. 12. The closed loop response of the integrated model has an advantage of having both a bypass door and fuel injector actuation for control purposes. The advantage can be seen as the normal shock position movement is reduced in the integrated model over that of just the inlet model alone. The integrated closed loop response has a maximum deviation of $0.01 \mathrm{~m}$ and the inlet model had a maximum deviation of $0.1 \mathrm{~m}$, approximately. This order of magnitude better attenuation illustrates a more rigorous control design coupling the inlet and engine control algorithms could provide a substantial improvement.

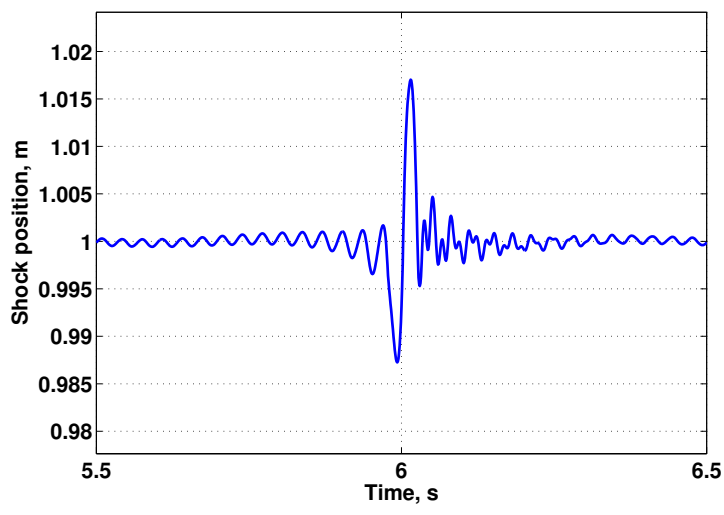

Figure 12. Integrated inlet and engine simulation, with closed-loop normal shock position control response to atmospheric disturbance.

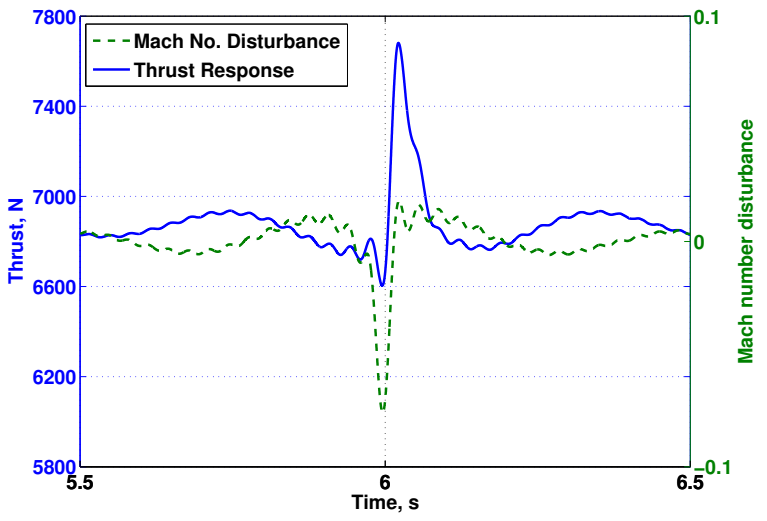

Figure 13. Simulated propulsion system net thrust oscillations due to atmospheric disturbances with closedloop normal shock position and rotor speed control.

Finally, the integrated model is used to show the closed loop net thrust oscillations due to an atmospheric disturbance, illustrated in Fig. 13. The nominal resulting net thrust from the integrated model is 6,900 N (1551 lbf). The larger sharp decrease in the free stream conditions that occurs at six seconds causes a large thrust oscillation. The mach number disturbance is plotted on the secondary y-axis to provide a reference of the time delay from the input disturbance to the resulting thrust oscillation. The larger transients cause an oscillation of approximately $1,100 \mathrm{~N}$ ( $247 \mathrm{lbf}$ ) or a $16 \%$ sudden change in the thrust of the propulsion system. This is a significant perturbation that warrants further investigation into the propulsion system effects on the vehicle.

\section{N+3 Variable Cycle Turbofan Engine Results}

The integrated model described in the previous section provides valuable modeling methodology verification and a preliminary test bed; however, the goal is to have an integrated model for the current design concepts of the supersonics project. In this section the $\mathrm{N}+3 \mathrm{VCE}$ engine results will be presented to test out the controller and examine a severe-case scenario for atmospheric disturbances with a potential to cause thrust oscillations at a cruise operating point. The engine controller component provides a reasonable initial look at the thrust oscillation suppression as opposed to including an inlet control, because the inlet being suggested for the supersonics project is an external compression inlet and will not have any of the inlet control actuators previously described. The external compression inlet will provide a large damping volume for the disturbances to attenuate before reaching the engine face, but no active control mechanisms are currently planned to help attenuate the disturbances. Thus, in this study the use of the engine model alone will provide a worst-case configuration, in the sense that without the inlet no damping volume is used to attenuate the atmospheric 
disturbances prior to reaching the engine face. Only the engine fuel injector that controls the fan speed will be used to dampen out any oscillations.

Results from the $\mathrm{N}+3 \mathrm{VCE}$ are all obtained at the operating point of $15,240 \mathrm{~m}$ $(50,000 \mathrm{ft})$ and Mach 1.6. The control performance was first examined by commanding the fan speed through a step up and step down transient with a $3 \%$ amplitude change. The results of this first test is shown in Fig. 14. The closed loop fan speed response illustrated in the upper plot of Fig. 14 shows an ability to track the commanded fan speed changes well with only small underdamped oscillations before settling on the steady state value. The lower illustration in Fig. 14 shows that a $3 \%$ change in the fan speed
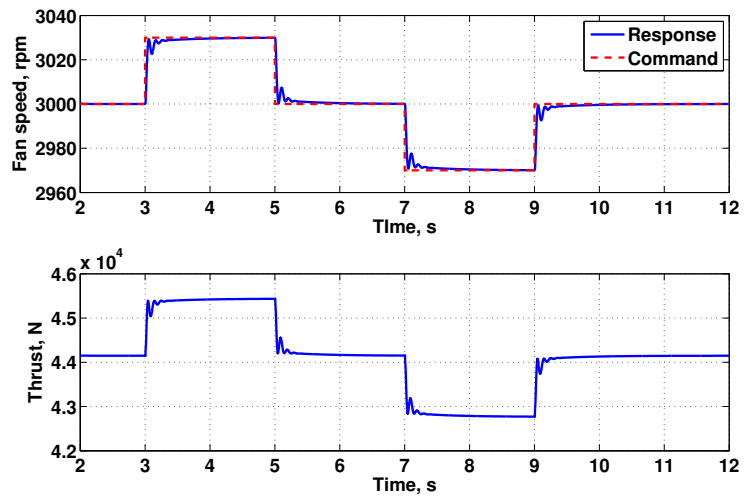

Figure 14. VCE fan speed command step changes controlled by fuel injector actuation and the resulting gross thrust change. results in a $3.2 \%$ change in the gross thrust produced by the engine from a steady state value of $44,100 \mathrm{~N}$ $(9,914 \mathrm{lbf})$.

The atmospheric turbulence model is applied to provide disturbances to the input boundary conditions of total pressure and temperature at the engine face. This is very similar to the boundary condition disturbances that were applied to the inlet, which are illustrated in Fig. 10. The distinction is that the velocity component of the disturbance that was used to excite a Mach number disturbance is not used for the input disturbance to the engine. The engine model only has the two upstream boundary conditions whereas the inlet has three upstream boundary conditions pertaining to the disturbances in Fig. 10. The Mach number disturbance could have been converted into an additional temperature disturbance, but was not considered for this study. Similar to the inlet atmospheric disturbance, a sum of sinusoids creates a repeating pattern that is representative of the one-second time slice. Again, the disturbance magnitude at the 6.0 second mark is a significant disturbance to the propulsion system.

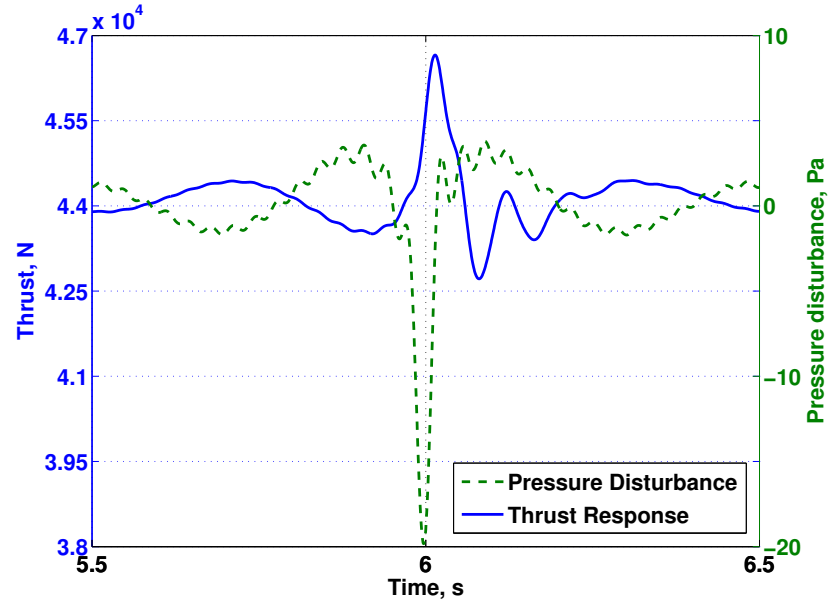

Figure 15. N+3 closed-loop gross thrust response to atmospheric disturbances at engine face, with a fan speed controller.

inlet is integrated with the engine; however, this prelimin cillation is significant enough to merit further study.

\section{Conclusion}

An integrated inlet and engine propulsion system component model has been developed and integrated with a control algorithm, where the inlet and engine components have previously been developed. The integrated propulsion system model presented in this work is suitable for incorporation into an overall supersonic vehicle aero-propulso-servo-elastic (APSE) model. The simulation includes an inlet normal shock 
position control and an engine rotor speed control for the propulsion system of a supersonic commercial transport. An atmospheric turbulence model is used to perturb the integrated propulsion model to illustrate system stability and expected thrust oscillations. The integrated propulsion system results illustrate that the inlet and engine controller allow for stable operation without a threat of an unstart condition for the single operating point investigated in this study. However, the thrust variation experienced has the potential to excite vehicle aero-elastic modes. The thrust oscillation obtained from the atmospheric disturbances was approximately a $15 \%$ variation from nominal. Such an oscillation will cause the aero-elastic modes of the vehicle to be impacted and further study of the coupling between these dynamics is required. A preliminary investigation of thrust oscillations induced by a severe atmospheric disturbance using a current supersonics project propulsion system concept, the next three generations $(\mathrm{N}+3)$ variable cycle engine $(\mathrm{VCE})$, without an inlet model was conducted. The thrust oscillations varied by approximately $10 \%$ about the nominal value, due to the disturbance. These results are expected to be a worst-case configuration, because the disturbance is placed directly at the engine face; however, there is potential for more severe atmospheric disturbances to be applied. The $10 \%$ magnitude thrust oscillation from the $\mathrm{N}+3 \mathrm{VCE}$ design concept could excite the aero-elastic modes of the vehicle and further study is required.

\section{References}

\footnotetext{
${ }^{1}$ Cohen, P., Long-Davis, M., and Povinelli, L., "Fundamental Aeronautics Program - Supersonics Project," http://www.aeronautics.nasa.gov/fap/documents.html, 2006.

${ }^{2}$ Perry, B., Silva, W., Florance, J., Wieseman, C., Potozky, A., Sanetrik, M., Scott, R., Keller, D., Cole, S., and Coulson, D., "Plans and Status of Wind Tunnel Testing Employing an Aeroservoelastic Semispan Model," 48th AIAA/ASME/ASCE/AHS/ASC Structural Dynamics, and Materials Conference, No. AIAA-2007-1770, April 2007.

${ }^{3}$ Kopasakis, G., Connolly, J., Paxson, D., and Ma, P., "Volume Dynamics Propulsion System Modeling for Supersonics Vehicle Research," Journal of Turbomachinery, Vol. 132, No. 4, October 2010, pp. 8.

${ }^{4}$ Connolly, J., Kopasakis, G., and Lemon, K., "Turbofan Volume Dynamics Model for Investigations of Aero-PropulsoServo-Elastic Effects in a Supersonic Commercial Transport," 46th AIAA/ASME/SAE/ASEE Joint Propulsion Conference and Exhibit, No. AIAA-2009-4802, Aug. 2009.

${ }^{5}$ Garrard, D., Davis, M., Wehofer, S., and Cole, G., "A One Dimensional, Time Dependent Inlet/Engine Numerical Simulation for Aircraft Propulsion Systems," ASME International Gas Turbine Institutes Turbo Expo, No. 97-GT-333, 1997.

${ }^{6}$ Garrard, D., "ATEC: The Aerodynamic Turbine Engine Code for the Analysis of Transient and Dynamic Gas Turbine Engine System Operations Part 1: Model Development," ASME International Gas Turbine Institutes Turbo Expo, No. 96-GT$193,1996$.

${ }^{7}$ Garrard, D., "ATEC: The Aerodynamic Turbine Engine Code for the Analysis of Transient and Dynamic Gas Turbine Engine System Operations Part 2: Numerical Simulations," ASME International Gas Turbine Institutes Turbo Expo, No. 96-GT-194, 1996.

${ }^{8}$ Gamble, E., Haid, D., D'Alessandro, S., and DeFrancesco, R., "Dual-Mode Scramjet Performance Model for TBCC Simulation," 45th AIAA/ASME/SAE/ASEE Joint Propulsion Conference and Exhibit, No. AIAA 2009-5298, 2009.

${ }^{9}$ Numbers, K. and Hamed, A., "Development of a Coupled Inlet-Engine Dynamic Analysis Method," 33rd AIAA/ASME/SAE/ASEE Joint Propulsion Conference and Exhibit, No. AIAA-1997-2880, 1997.

${ }^{10}$ Giannola, P., Haas, M., Cole, G., and Melcher, K., "Modeling the Dynamics of Superonic Inlet/Gas Turbine Engine Systems for Large - Amplitude High Frequency Disturbances," 36th AIAA/ASME/SAE/ASEE Joint Propulsion Conference and Exhibit, No. A00-36772, 2000.

${ }^{11}$ Kopasakis, G., "Atmospheric Turbulence Modeling for Aero Vehicles: Fractional Order Fits," Tech. rep., NASA TM 2010-216961, Jan. 2010.

${ }^{12}$ Kopasakis, G., "Modeling of Atmospheric Turblence as Disturbances for Control Design and Evaluation of High Speed Propulsion Systems," Proceedings of ASME Turbo Expo 2010: Power for Land, Sea and Air, No. GT2010-22851, Glasgow, UK, June 14-18 2010.

${ }^{13}$ Kopasakis, G., "Feedback Control Systems Loop Shaping Design with Practical Considerations," Tech. rep., NASA TM 2007-215007, September 2007.

${ }^{14}$ Houpis, C., Rasmussen, S., and Sanz, M., Quantitative Feedback Theory: Foundamentals and Applications, Taylor Francis, 2006.

${ }^{15}$ Connolly, J. and Kopasakis, G., "Loop Shaping Control Design for a Supersonic Propulsion System Model Using QFT Specifications and Bounds," 46th AIAA/ASME/SAE/ASEE Joint Propulsion Conference and Exhibit, No. AIAA-2010-7086, 2010.

${ }^{16}$ Chavez, F. and Schmidt, D., "Analytical Aeropropulsive/Aeroelastic Hypersonic - Vehicle Model with Dynamic Analysis," Journal of Guidance, Control, and Dynamics, Vol. 17, No. 6, December 1994, pp. 1308-1319.
} 
${ }^{17}$ Nguyen, N., "Integrated Flight Dynamic Modeling of Flexible Aircraft with Inertial Force-Propulsion-Aeroelastic Coupling," 44th AIAA Aerospace Sciences Meeting and Exhibit, No. AIAA 2008-194, Reno, Nevada, 7-10 January 2008.

${ }^{18}$ Clark, A., Wu, C., Mirmirani, M., and Choi, S., "Development of an Airframe-Propulsion Integrated Generic Hypersonic Vehicle Model," 46th AIAA Aerospace Sciences Meeting and Exhibit, No. AIAA 2006-218, Reno, Nevada, 9-12 January 2006.

${ }^{19}$ Pratt Whitney and General Electric, "Critical Propulsion Components: Inlet and Fan/Inlet Accoustics Team," Tech. rep., NASA CR-2005-213584, 2005.

${ }^{20}$ Kopasakis, G., Connolly, J., Paxson, D., and Woolwine, K., "Quasi 1D Modeling of Mixed Compression Supersonic Inlets," 50th AIAA Aerospace Sciences Meeting including the New Horizons Forum and Aerospace Exposition, No. TBD, Jan. To Be Published.

${ }^{21}$ Anderson, J., "Computational Fluid Dynamics: The Basics with Applications," McGraw Hill, New York, NY, 1995.

${ }^{22}$ Varner, M., Martindal, W., Phares, W., Kneile, K., and Adams, J., "Large Perturbation Flow Field Anaylsis and Simulation for Supersonic Inlet," Tech. rep., NASA CR-174676, 1985.

${ }^{23}$ Hill, P. and Peterson, C., "Mechanics and Thermodynamics of Propulsion," Prentice Hall, 1991.

${ }^{24}$ Saunders, J., Research and Technology 1998, Two-Dimensional Bifurcated Inlet/Engine Tests Completed in 10 by 10 Foot Supersonic Wind Tunnel, NASA TM 1999-208815, 1999.

${ }^{25}$ Seldner, K., Mihaloew, J., and Blaha, R., "Generalized Simulation Technique for Turbojet Engine System Analysis," Tech. rep., NASA TN-D-6610, 1972.

${ }^{26}$ Tesch, W. and Steenken, W., "Blade Row Dynamic Digital Compressor Program. Volume I: J85 Clean Inlet Flow and Parallel Compressor Models," Tech. rep., NASA CR-134978, 1976.

${ }^{27}$ Horowitz, I., "Quantitative Feedback Theory," IEEE Proceedings, Vol. 129, No. 6, Nov. 1982, pp. 215-226.

${ }^{28}$ Kopasakis, G. and Connolly, J., "Shock Positioning Controls Design for a Supersonic Inlet," 46th AIAA/ASME/SAE/ASEE Joint Propulsion Conference and Exhibit, No. AIAA-2009-2803, Aug. 2009.

${ }^{29}$ Sanders, B. and Mitchell, G., "Throat-Bypass Bleed Systems for Increasing the Stable Airflow Range of a Mach 2.5 Axisymmetric Inlet with 40- Percent Internal Contraction," Tech. rep., NASA TM X-2779, 1973. 


\begin{tabular}{|c|c|c|}
\hline \multicolumn{2}{|c|}{ REPORT DOCUMENTATION PAGE } & $\begin{array}{l}\text { Form Approved } \\
\text { OMB No. 0704-0188 }\end{array}$ \\
\hline \multicolumn{3}{|c|}{ 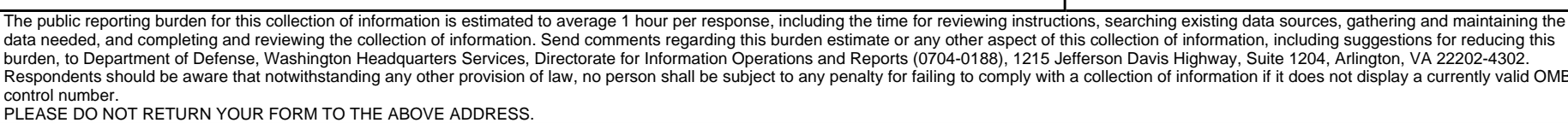 } \\
\hline $\begin{array}{l}\text { 1. REPORT DATE (DD-MM-YYYY) } \\
01-03-2012\end{array}$ & $\begin{array}{l}\text { 2. REPORT TYPE } \\
\text { Technical Memorandum }\end{array}$ & 3. DATES COVERED (From - To) \\
\hline \multirow{3}{*}{\multicolumn{2}{|c|}{$\begin{array}{l}\text { 4. TITLE AND SUBTITLE } \\
\text { Nonlinear Dynamic Modeling and Controls Development for Supersonic Propulsion System } \\
\text { Research }\end{array}$}} & 5a. CONTRACT NUMBER \\
\hline & & 5b. GRANT NUMBER \\
\hline & & 5c. PROGRAM ELEMENT NUMBER \\
\hline \multirow{3}{*}{\multicolumn{2}{|c|}{$\begin{array}{l}\text { 6. AUTHOR(S) } \\
\text { Connolly, Joseph, W.; Kopasakis, George; Paxson, Daniel, E.; Stuber, Eric; Woolwine, Kyle }\end{array}$}} & 5d. PROJECT NUMBER \\
\hline & & 5e. TASK NUMBER \\
\hline & & $\begin{array}{l}\text { 5f. WORK UNIT NUMBER } \\
\text { WBS 984754.02.07.03.20.02 }\end{array}$ \\
\hline \multicolumn{2}{|c|}{$\begin{array}{l}\text { 7. PERFORMING ORGANIZATION NAME(S) AND ADDRESS(ES) } \\
\text { National Aeronautics and Space Administration } \\
\text { John H. Glenn Research Center at Lewis Field } \\
\text { Cleveland, Ohio 44135-3191 }\end{array}$} & $\begin{array}{l}\text { 8. PERFORMING ORGANIZATION } \\
\text { REPORT NUMBER } \\
\text { E-18029 }\end{array}$ \\
\hline \multirow{2}{*}{\multicolumn{2}{|c|}{$\begin{array}{l}\text { 9. SPONSORING/MONITORING AGENCY NAME(S) AND ADDRESS(ES) } \\
\text { National Aeronautics and Space Administration } \\
\text { Washington, DC 20546-0001 }\end{array}$}} & $\begin{array}{l}\text { 10. SPONSORING/MONITOR'S } \\
\text { ACRONYM(S) } \\
\text { NASA }\end{array}$ \\
\hline & & $\begin{array}{l}\text { 11. SPONSORING/MONITORING } \\
\text { REPORT NUMBER } \\
\text { NASA/TM-2012-217273 }\end{array}$ \\
\hline \multicolumn{3}{|c|}{$\begin{array}{l}\text { 12. DISTRIBUTION/AVAILABILITY STATEMENT } \\
\text { Unclassified-Unlimited } \\
\text { Subject Category: } 07 \\
\text { Available electronically at http://www.sti.nasa.gov } \\
\text { This publication is available from the NASA Center for AeroSpace Information, 443-757-5802 }\end{array}$} \\
\hline
\end{tabular}

\section{ABSTRACT}

This paper covers the propulsion system component modeling and controls development of an integrated nonlinear dynamic simulation for an inlet and engine that can be used for an overall vehicle Aero-Propulso-Servo-Elastic (APSE) model. The focus here is on developing a methodology for the propulsion model integration, which allows for controls design that prevents inlet instabilities and minimizes the thrust oscillation experienced by the vehicle. Limiting thrust oscillations will be critical to avoid exciting vehicle aeroelastic modes. Model development includes both inlet normal shock position control and engine rotor speed control for a potential supersonic commercial transport. A loop shaping control design process is used that has previously been developed for the engine and verified on linear models, while a simpler approach is used for the inlet control design. Verification of the modeling approach is conducted by simulating a twodimensional bifurcated inlet and a representative J-85 jet engine previously used in a NASA supersonics project. Preliminary results are presented for the current supersonics project concept variable cycle turbofan engine design.

15. SUBJECT TERMS

Propulsion; Thrust; Control theory

\begin{tabular}{|c|c|c|c|c|c|}
\hline \multicolumn{3}{|c|}{ 16. SECURITY CLASSIFICATION OF: } & \multirow{2}{*}{$\begin{array}{l}\text { 17. LIMITATION OF } \\
\text { ABSTRACT } \\
\text { UU }\end{array}$} & \multirow{2}{*}{$\begin{array}{l}\text { 18. NUMBER } \\
\text { OF } \\
\text { PAGES } \\
21\end{array}$} & \multirow{2}{*}{$\begin{array}{l}\text { 19a. NAME OF RESPONSIBLE PERSON } \\
\text { STI Help Desk (email:help@sti.nasa.gov) } \\
\text { 19b. TELEPHONE NUMBER (include area code) } \\
\text { 443-757-5802 }\end{array}$} \\
\hline $\begin{array}{l}\text { a. REPORT } \\
\text { U }\end{array}$ & $\begin{array}{l}\text { b. ABSTRACT } \\
U\end{array}$ & $\begin{array}{l}\text { c. THIS } \\
\text { PAGE } \\
\text { U }\end{array}$ & & & \\
\hline
\end{tabular}


